See discussions, stats, and author profiles for this publication at: https://www.researchgate.net/publication/298426127

\title{
DNA barcoding to identify species of phlebotomine sand fly (Diptera: Psychodidae) in the mixed leishmaniasis focus of the Colombian Caribbean
}

Article in Acta tropica · March 2016

DOI: 10.1016/j.actatropica.2016.03.017

CITATIONS

13

4 authors, including:

Luis Roberto Romero

Universidad de Sucre

4 PUBLICATIONS 26 CITATIONS

SEE PROFILE
READS

218

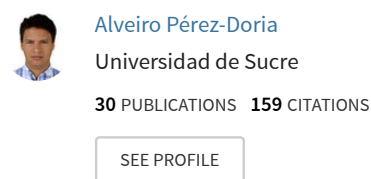

Some of the authors of this publication are also working on these related projects:

Barcoding DNA of Lutzomyia spp. in the Caribbean coast View project

IDENTIFICACIÓN DE LOS CRIADEROS NATURALES DE ESPECIES DEL GÉNERO Lutzomyia (Diptera: Psychodidae), EN LA CIUDAD DESINCELEJO, DEPARTAMENTO DE SUCRE View project 


\section{Accepted Manuscript}

Title: DNA barcoding to identify species of phlebotomine sand fly (Diptera: Psychodidae) in the mixed leishmaniasis focus of the Colombian Caribbean

Author: Luis Romero-Ricardo Natalia Lastre Alveiro Pérez-Doria Eduar E. Bejarano

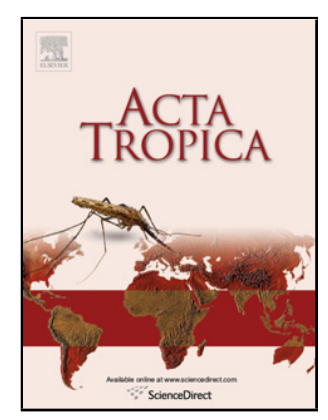

PII: S0001-706X(16)30107-3

DOI: http://dx.doi.org/doi:10.1016/j.actatropica.2016.03.017

Reference: ACTROP 3889

To appear in: Acta Tropica

Received date: 22-9-2015

Revised date: 25-1-2016

Accepted date: $14-3-2016$

Please cite this article as: Romero-Ricardo, Luis, Lastre, Natalia, Pérez-Doria, Alveiro, Bejarano, Eduar E., DNA barcoding to identify species of phlebotomine sand fly (Diptera: Psychodidae) in the mixed leishmaniasis focus of the Colombian Caribbean.Acta Tropica http://dx.doi.org/10.1016/j.actatropica.2016.03.017

This is a PDF file of an unedited manuscript that has been accepted for publication. As a service to our customers we are providing this early version of the manuscript. The manuscript will undergo copyediting, typesetting, and review of the resulting proof before it is published in its final form. Please note that during the production process errors may be discovered which could affect the content, and all legal disclaimers that apply to the journal pertain. 
DNA barcoding to identify species of phlebotomine sand fly (Diptera: Psychodidae) in the mixed leishmaniasis focus of the Colombian Caribbean

Luis Romero-Ricardo*, Natalia Lastre, Alveiro Pérez-Doria, Eduar E. Bejarano

Investigaciones Biomédicas group, Universidad de Sucre, Sincelejo, Sucre, Colombia

* Corresponding author at: Group de Investigaciones Biomédicas, Universidad de Sucre, Cra. 14

No. 16B-32, Sincelejo, Sucre, CP 700003, Colombia. Tel.: +57 52820830; fax: +57 52821240

E-mail address: luisro987@gmail.com (L. Romero-Ricardo)

Graphical abstract 

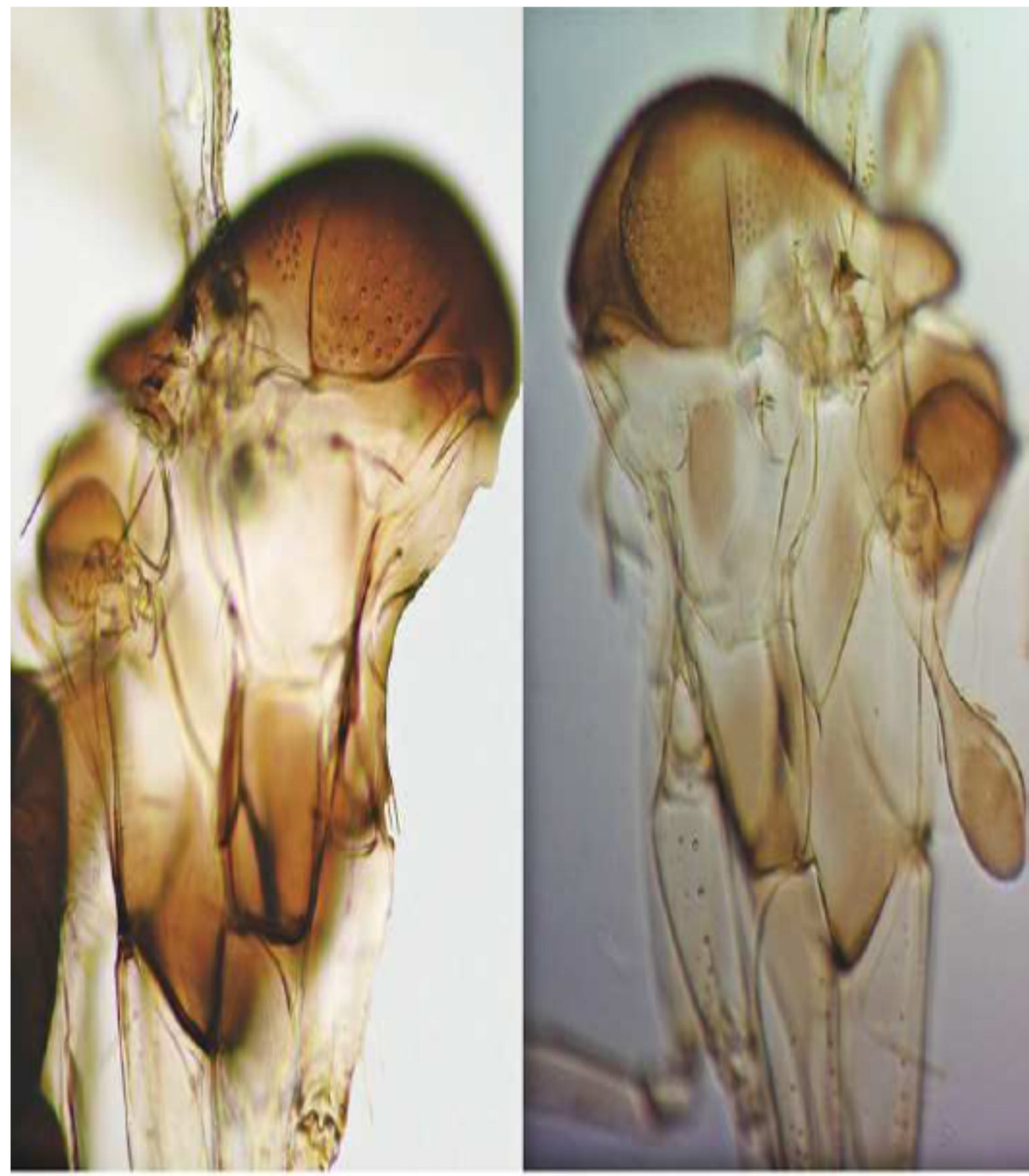

A

B

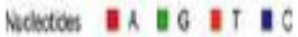
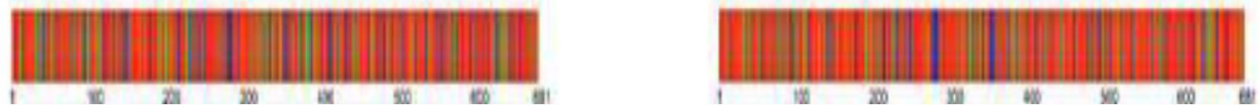

Highlights 
- DNA barcoding can be used to identify 20 species of phlebotomine sand flies of the Colombian Caribbean.

- Phlebotomine sand flies are correctly assigned to species by any of the evolutionary three models (TN93, K2P or p-distances).

- Morphologically similar species of phlebotomine sand flies can be separated using DNA barcoding.

- At the supraspecific level the phylogenetic signal of the gene COI is lost due to substitutional saturation.

\section{ABSTRACT}

Identification of the species of phlebotomine sand flies present in each focus of leishmaniasis is necessary to incriminate vectors and implement vector control strategies. Although the cytochrome oxidase I (COI) gene has been proposed as a barcode for the identification of animal species, less than $20 \%$ of New World phlebotomines have been characterized to date. In this study DNA barcoding was used to identify phlebotomine species of the mixed leishmaniasis focus in the Colombian Caribbean by means of three evolutionary models: Kimura's two parameter (K2P) nucleotide substitution model, that of Tamura \& Nei (TN93) and proportional sequence divergence (pdistances). A $681 \mathrm{bp}$ sequence of the COI gene was obtained from 66 individuals belonging to 19 species of the genus Lutzomyia (Lu. abonnenci, Lu. atroclavata, Lu. bicolor, Lu. carpenteri, Lu. cayennensis, Lu. dubitans, Lu. evansi, Lu. gomezi, Lu. gorbitzi, Lu. longipalpis, Lu. micropyga, Lu. migonei, Lu. panamensis, Lu. (Psathyromyia) sp., Lu. rangeliana, Lu. serrana, Lu. shannoni, Lu. trinidadensis and Lu. venezuelensis) and one of Brumptomyia (B. mesai). The genetic divergence values for TN93 among individuals of the same species fluctuated up to 3.2\% (vs. 2.9\% for K2P and $2.8 \%$ for p-distances), while the values between species ranged from $8.8-43.7 \%$ (vs. $6.8-19.6 \%$ for $\mathrm{K} 2 \mathrm{P}$ and $6.6-17.4 \%$ for p-distances). A dendrogram constructed by means of the NeighborJoining method grouped phlebotomines into 20 clusters according to species, with bootstrap values of up to $100 \%$ in those with more than one individual. However, loss of the phylogenetic signal of the gene COI was observed at the supraspecific level as a consequence of substitutional saturation. In 
conclusion, irrespective of the evolutionary model selected, all phlebotomines were correctly assigned to species, showing $100 \%$ concordance with morphological identification. Keywords: Lutzomyia, Sand flies, DNA barcoding, cytochrome oxidase I (COI), Species identification.

\section{Introduction}

The genus Lutzomyia (Lu.) comprises about 500 species distributed throughout North, Central and South America. Approximately 56 species of this genus have been incriminated as vectors of parasites of the genus Leishmania (Maroli et al., 2013), etiological agents of the distinct clinical forms of leishmaniasis. In Colombia, the departments of Bolívar, Córdoba and Sucre constitute the most important mixed focus of leishmaniasis in the Caribbean from which $83 \%$ of the cases of cutaneous leishmaniasis and all the visceral cases in the region are reported (INS, 2005-2015).

The systematics of the New World phlebotomine sand flies have been reviewed by several taxonomic schools, each with its own techniques, foundations and hypotheses (Baretto, 1955, 1962; Fairchild, 1955; Theodor, 1965; Forattini, 1973; Abonnenc \& Leger, 1976; Lewis et al., 1977; Martins et al., 1978; Young, 1979; Artemiev, 1991; Young \& Duncan, 1994; Galati 2003a, b). These differ in the use and weight assigned to certain morphological characters and the way of grouping the taxa at supraspecific level. Nevertheless, all face the same challenges with regard to the taxonomic determination of certain species which, as well as presenting isomorphism in anatomical structures employed as diagnostic characters, may often be found in sympatry (Scarpassa \& Alencar, 2013).

This has motivated the search for alternative systems of taxonomic identification based on molecular characters, some of which have proved to be useful in resolving questions at infraspecific or supraspecific levels (Bejarano, 2001). These have been based on both nuclear and mitochondrial genes, with the latter predominating (Depaquit, 2014). However, the great diversity of molecular 
markers used has complicated the analysis and global comparison of all phlebotomine sand fly species (Bejarano, 2002). Faced with this situation, the use of a universal barcoding system has been proposed to facilitate integration of knowledge on the genetic diversity of phlebotomines and allow comparisons to be made between the insects from a particular area and those from the type locality, to confirm their identities, promote the exchange of ideas and test evolutionary hypotheses within a global scenario.

Although the gene cytochrome $\mathrm{C}$ oxidase (COI) has been proposed for DNA barcoding of the animal kingdom (Hebert et al., 2003, 2004) to date the number of sand fly species characterized in the New World by this method is less than 100 (Azpurua et al., 2010; Cohnstaedt et al., 2011; Hoyos et al., 2012; Scarpassa \& Alencar, 2013; Contreras-Gutiérrez et al., 2014; Kato et al., 2015; Nzelu et al., 2015), corresponding to less than $20 \%$ of the diversity known in the Americas (Young \& Duncan, 1994; Galati, 2003a). Most studies with DNA barcoding have employed Kimura's two-parameter model (1980) (K2P) to construct trees, generally assuming a priori that the suppositions of this model explain polymorphism in the COI nucleotide sequences. However, this position has been questioned in recent years (Srivathsan \& Meier, 2012), particularly as COI could be associated with a particular evolutionary model in each group of organisms.

Different tools are now available (Modeltest, DT-ModSel, jModeltest, Best DNA model-MEGA) that can test various models and use probability to find the one that best adjusts to the data. Thus, in the present study the use of DNA barcoding was evaluated by means of three models of nucleotide substitution, to identify species of the genus Lutzomyia present in the focus of cutaneous and visceral leishmaniasis in the Colombian Caribbean.

\section{Materials and methods}

\subsection{Study area}

Fieldwork was carried out in the municipalities of Colosó, Sincelejo and Ovejas, in the Caribbean departament of Sucre, Colombia. According to the life zones defined by Holdridge (1967), this region 
is characterized by dry tropical forest, with mean annual temperatures of $28^{\circ} \mathrm{C}$, relative humidity of up to $90 \%$, rainfall of up to $1050 \mathrm{~mm}$ per year, and elevations of less than 1000 masl. The three localities described were selected for sampling based on previous studies which had revealed both a considerable degree of phlebotomine diversity and prevalence of leishmaniasis (Bejarano et al., 2007; Pérez-Doria et al., 2008a; Pérez-Doria et al., 2009).

\subsection{Collection of phlebotomine sand flies and morphological determination of species}

Collection of phlebotomine sand flies was carried out between December 2008 and June 2009 by means of CDC light traps, Shannon traps and active searches in diurnal resting sites using mouth and electric aspirators. The entomological material captured was transported dry to the Biomedical Research Laboratory at the University of Sucre in Sincelejo. Sand flies were then separated under a Stemi 2000-C stereoscope, the three terminal segments of the abdomen and head being removed from each specimen to carry out taxonomic determination using keys and reference descriptions (Young \& Duncan, 1994; Galati, 2011). The thorax and part of the abdomen were stored in $70 \%$ ethanol prior to revision of morphological characters of taxonomic interest. One to six individuals per species were selected for the molecular study from the specimens identified.

\subsection{Molecular determination of species}

\subsubsection{Extraction of DNA, polymerase chain reaction and electrophoresis}

Each phlebotomine selected for the molecular study was submitted to DNA extraction using a high salt concentration protocol described in detail by Pérez-Doria et al. (2008b). DNA amplification was subsequently carried out with the primers LCO1490 and HCO2198 (Folmer et al., 1994), which delimit a 710 bp segment of the COI gene. Polymerase chain reaction (PCR) was carried out in a volume of $25 \mu \mathrm{L}$ which contained 1X PCR buffer, $1.5 \mathrm{mM} \mathrm{MgCl}_{2}, 100 \mu \mathrm{M}$ of each dNTP, $0.3 \mu \mathrm{M}$ of each primer, 1 unit of Taq Polymerase and $1-3 \mu \mathrm{L}(6 \mathrm{ng} / \mu \mathrm{L}-40 \mathrm{ng} / \mu \mathrm{L})$ of the extracted DNA solution. 
Amplification was performed in a C1000 thermocycler (BioRad Laboratories) under the thermal profile described by Herbert et al. (2003). The amplification products were subjected to electrophoresis in $0.75 \%$ agarose gel stained with GelStar, applying 75 volts during 45 minutes. Amplicon size was determined using a GeneRuler ${ }^{\mathrm{TM}}$ marker of molecular weight $1 \mathrm{~Kb}$ and a VisiBlue transilluminator (UVP Systems) was used to visualize the gels.

\subsubsection{Sequencing and genetic analysis}

The PCR products obtained were purified and then sequenced in both senses of the DNA chain using a 3730XL automatic capillary electrophoresis sequencer. The electrophoregrams were edited manually with the help of the Trace Data File Viewer/Editor function of the Molecular Evolutionary Genetic Analysis (MEGA 5) program (Tamura et al., 2011). The consensus sequence of each individual was assembled with the MEGA 5 Alingment Explorer. The sequence generated was analyzed by means of the Basic Local Alignment Search Tool (BLAST) (Altschul et al., 1990). The consensus sequences were aligned with the CLUSTAL W program, also included in MEGA 5.

The DnaSP v5 program (Librado \& Rozas, 2009) was used to obtain descriptive information on the sequences, including the number of polymorphic sites and haplotypes per species. The online program FINGERPRINT (Lou \& Golding, 2007) was also used to generate graphs of nucleotide heterogeneity showing how variation between nucleotides was distributed within the multiple alignment.

The jModelTest program (Posada, 2008) was used for statistical selection of the nucleotide substitution model that best fitted the set of sequences studied. Genetic divergence values were also calculated with MEGA 5 for the K2P model, employed traditionally "by default" as part of DNA barcoding methodology, as well as for the proportional sequence divergence (p-distances), which in some cases have shown a utility equal to or superior to that of K2P (Srivathsan \& Meier, 2012). The existence of a "barcoding gap" between the intra and interspecific variability detected on the dataset was determined based on the genetic distances obtained. 
Using the distances calculated for the different evolutionary models, a dendrogram was developed by the Neighbour-Joining (NJ) method (Saitou \& Nei, 1987). Species-monophyly was evaluated based on the topology of the resulting tree. In order to detect whether the molecular marker presented substitutional saturation, the progression of the number of transitions and transversions relative to the genetic distances was analyzed using the Data Analysis and Molecular Biology and Evolution (DAMBE) program version 5.6.6 (Xia \& Xie, 2001). Additionally, each position of the codon was submitted separately to the substitution saturation test of Xia et al. (2003), again using DAMBE 5.6.6. It was determined whether the observed index of substitution saturation (Iss) was significantly higher or lower than the critical value of the index of substitution saturation (Iss.c), assuming that when Iss>Iss.c this indicates that severe substitution saturation has occurred and Iss $<$ Iss.c means that the sequences have experienced little substitutional saturation (Xia \& Lemey, 2009). The nucleotide sequences were then consigned onto Genebank using the Sequin 9.5 program (Benson et al., 2010).

\section{Results}

In all 66 nucleotide sequences of $681 \mathrm{bp}$ of the COI gene were obtained, belonging to one species of the genus Brumptomyia and 19 species of Lutzomyia (Table 1). This latter genus was represented by the subgenera Lutzomyia, Micropygomyia, Nyssomyia, Psathyromyia and Psychodopygus, and the species groups Aragaoi, Baityi, Migonei, Oswaldoi and Verrucarum. The sequences were recorded on Genebank with access numbers ranging from GU909444 - GU909510 (Table 1). The sequenced fragment is homologous to the region lying between positions 1468 and 2148 of the COI gene in the mitochondrial genome of Lu. umbratilis (KP702938, Kocher et al., 2015). Analysis of the set of sequences with the program BLAST provided coverages of $80-100 \%$, and similarities of the $86-$ 99\% with the COI of New World phlebotomine sand flies recorded in previous studies (Azpurua et al., 2010; Cohnstaedt et al. 2011; Hoyos et al., 2012; Scarpassa \& Alencar, 2013; Contreras-Gutiérrez et al., 2014; Nzelu et al., 2015). 
About two-thirds (66.6\%) of the nucleotide composition of the 66 sequences of the COI gene was made up of adenine and thymine, with guanine and cytosine constituting the remaining $33.4 \%$. Heterogeneity per nucleotide site is shown in Fig. 1A. In the multiple alignment of 681 nucleotides, 242 polymorphic sites were observed, four of them being singleton sites and 238 corresponding to phylogenetically informative sites of up to four variants, distributed along the alignment (Fig. 1B). The number of haplotypes per species varied between one and five (Table 1), the highest values being seen in Lu. rangeliana, Lu. shannoni and Lu. atroclavata.

The polymorphism present in the nucleotide sequences contrasted with the high degree of similarity presented by the amino acid sequences. In the multiple alignment of 227 amino acids (data not shown), only 12 variable sites were found, as well as eight phylogenetically informative sites of up to three variants and two singleton sites. It is important to emphasize that stop codons or indel type mutations were not encountered in the amino acid sequences inferred from each DNA sequence, so that amplification of pseudogenes or nuclear copies of mitocondrial origin (NUMTs) can be discounted.

The evolutionary model that best fitted the dataset was that of Tamura \& Nei (1993) (TN93), incorporating the shape parameter of the gamma distribution $(\mathrm{G}=0.2650)$ and the proportion of invariable sites $(I=0.4730)$. Values of intraspecific genetic divergence calculated with the K2P model varied up to $2.9 \%$ (Table 1), while the interspecific ones were between $6.8 \%$ and $19.6 \%$ (Table 2). For the TN93 model values of intraspecific divergence achieved a maximum value $3.2 \%$ (Table 1), while the interspecific ones ranged from 8.8 to $43.7 \%$ (Table 2). Finally in the p-distances, the intraspecific margin was up to $2.8 \%$, while the interspecific one varied from $6.6 \%$ to $17.4 \%$ (Fig. S1).

In the dendrograms constructed by the NJ method with the TN93, K2P (Fig. 2) and p-distance (Fig. S2) models, it was found that species with more than one individual could be unequivocally grouped into 16 clusters, supported with bootstrap values of up to $100 \%$. With regard to the 
interspecific relationships, only the clusters which grouped $L u$. shannoni and Lu. abonnenci, as well as those linking $L u$. venezuelensis and Lu. atroclavata, showed high bootstrap values, of up to $100 \%$.

In the graph of transitions and transversions vs. genetic distance for TN93 (Fig. S3), the number of the latter exceded that of the former when divergence reached 3\%. A similar result was obtained when the analysis was performed with K2P distances (data not shown). Additionally, the saturation test of Xia et al. (2003) showed that the Iss $=0.114$ and 0.004 , of the first and second codon positions, respectively, were significantly lower $(P<0.0001)$ than the Iss.c $=0.685$ and 0.364 for symmetrical and asymmetrical topology. It is thus inferred that both positions have undergone little substitutional saturation. For the third codon position, the Iss $=0.562$ was significantly lower $(P=0.0003)$ than the Iss.c $=0.685$ for symmetrical topology, but significantly higher $(P<0.0001)$ than the Iss.c $=0.364$ for asymmetrical topology. It can therefore be concluded that the marker has undergone a substantial saturation on the third position of the codon.

\section{Discussion}

One of the most common limitations of the molecular markers proposed for genotyping is their inability to identify correctly species that diverged recently (van Velzen et al., 2012). DNA barcoding constitutes a rapid and trustworthy tool that with some exceptions (Laurito et al., 2013), has demonstrated the capacity to differentiate closely related species based on the analysis of a small portion of the genome (Hebert et al., 2003). The present study confirms once more the use of the gene COI as a barcode for the identification of phlebotomine sand flies, this time in 19 species of the genus Lutzomyia and one of Brumptomyia of the Colombian Caribbean. In the present study DNA barcodes were generated for the species Lu. abonnenci, Lu. atroclavata, Lu. bicolor, Lu. dubitans, Lu. micropyga, Lu. migonei, Lu. rangeliana and Lu. venezuelensis for the first time. Additionally, new DNA barcodes were provided for Lu. carpenteri, Lu. c. cayennensis, Lu. evansi, Lu. gomezi, Lu. gorbitzi, Lu. longipalpis, Lu. panamensis, Lu. serrana, Lu. shannoni, Lu. trinidadensis and B. mesai. 
To date, K2P has been the preferred model of nucleotide substitution employed in DNA barcoding of phlebotomine sand flies (Azpurua et al., 2010; Cohnstaedt et al., 2011; Hoyos et al., 2012; Scarpassa \& Alencar, 2013; Contreras-Gutiérrez et al., 2014; Nzelu et al., 2015), based on the original studies of Hebert et al. (2003). However, the selection of K2P as the standard model has been questioned (Srivathsan \& Meier, 2012), as well as the use of mean rather than smallest interspecific divergence values to estimate the so-called "barcoding gap" between intra- and interspecific variability (Meier et al., 2008). In consequence attention has been drawn to the need both to establish which model of nucleotide substitution could best be fitted to each dataset, as well using the smallest interspecific divergence values to estimate the barcoding gap.

In the present study TN93 was the evolutionary model that best adjusted to the set of 66 sequences analyzed. However, the intraspecific divergence values calculated for TN93 were equal or close to those generated for $\mathrm{K} 2 \mathrm{P}$, while those of the p-distances were generally lower than those of both models. The maximum intraspecific genetic divergence value of $2.9 \%$ obtained for $\mathrm{K} 2 \mathrm{P}$, the only model comparable with previous studies, is twice as small as the $6 \%$ previously recorded in species of the genera Lutzomyia and Brumptomyia of Colombia (Contreras-Gutiérrez et al., 2014). This difference could be explained by the limited number of individuals sequenced per species, which in the present study varied between two and six. By contrast, the minimum value for interspecific genetic divergence based on $\mathrm{K} 2 \mathrm{P}$ of $6.8 \%$ is lower than the $9 \%$ reported for the taxon in Colombia (Contreras-Gutiérrez et al., 2014), which could be attributed to differences in the collection site of sandflies and the size of the fragment analyzed, which reached 549 nucleotides in some of the sequences generated by the previous study.

Irrespective of the evolutionary model selected, Lu. dubitans and Lu. rangeliana exhibited the highest values of intraspecific genetic divergence. They also presented the greatest number of haplotypes per species, most of which were found in the same locality. The four haplotypes of $L u$. dubitans were found in Colosó, while four of the five Lu. rangeliana ones were encountered in 
Ovejas. This is probably due to the presence of species with populations more conserved than others, influenced by random genetic changes (Florin et al., 2011).

On the other hand, the lowest value of interspecific genetic divergence was observed between Lu. abonnenci and Lu. shannoni, which between them presented 40 nucleotide variable positions. Based on this $6.8 \%$ was established as the minimum K2P divergence value (8.8\% for TN93) from which the phlebotomine species of the leishmaniasis focus studied could be differentiated. The latter does not overlap with the maximum intraspecific divergence value by K2P of 2.9\% (3.2\% for TN93), confirming the existence of a barcoding gap in the dataset analyzed. However it cannot be ignored that the minimum interspecific divergence value of $6.8 \%$ recorded in this study is close to the maximum intraspecific value $(6 \%)$ reported in Colombian sand flies by Contreras-Gutiérrez et al. (2014), probably due to differences in the populations and species studied, the number of individuals and the size of the COI segment analyzed. This would reduce the present barcoding gap for phlebotomine sand flies of Colombia, which constitutes one of the pillars on which barcoding methodology is based (Hebert et al., 2003). For this reason, these margins should be re-estimated in future by means of an analysis that encompasses all the sequences of phlebotomine sand flies available and incorporates individuals of the same species from distinct geographical populations.

Using any of the three evolutionary models evaluated, the species separated into 20 clusters on the NJ dendrogram, showing $100 \%$ concordance with the initial morphological identification, 16 of these clusters showed robust branch support, similar to that recorded in previous studies (Azpurua et al., 2010; Kumar et al., 2012; Contreras-Gutiérrez et al., 2014). It is noteworthy that in the subgenus Micropygomyia, the molecular marker permitted separation of the species Lu. c. cayennensis and Lu. micropyga, as well as Lu. venezuelensis and Lu. atroclavata, which present considerable similarities in their morphological structures.

Although the marker allow all the species studied to be distinguished, evolutionary relationships among species and subgenera were not always consistent with the existing taxonomic proposals based on morphology (Young \& Duncan, 1994; Galati, 2003a), except for some closely related species that 
appeared under the same node with a high bootstrap value such as Lu. shannoni and Lu. abonnenci of the subgenus Psathyromyia, as well as Lu. venezuelensis and Lu. atroclavata of the subgenus Micropygomyia. This loss of phylogenetic signal at the supraspecific level can be attributed to mutational saturation of the COI gene in percentages of genetic divergence greater than $3 \%$, as a consequence of the high mutation rate of the mitochondrial genome, particularly on the third position of the codon, which would mask nucleotide substitutions (Roe \& Sperling, 2007). This would explain why some pairs of morphologically similar species such as Lu. micropyga and Lu. c. cayennensis of the subgenus Micropygomyia, Lu. evansi and Lu. serrana of the group Verrucarum, and Lu. migonei and Lu. dubitans of the Migonei group, appear under the same node but with low bootstrap values $(<50 \%)$

\section{Conclusions and perspectives}

DNA barcoding was useful for the identification of 20 species of phlebotomine sand flies of the mixed leishmaniasis focus of the Colombian Caribbean. Irrespective of the evolutionary model selected to calculate genetic divergence, all the phlebotomine sand flies were correctly assigned to species by TN93, K2P or p-distances, in $100 \%$ concordance with their morphological identification. Based on our confirmation of its validity we call on the taxonomists working with New World phlebotomine sand flies to obtain further DNA barcodes, especially of the species endemic to their respective countries. DNA barcoding provides an opportunity to resolve the specific status of those species that have remained informally described for decades. Taking into account the observed loss of the phylogenetic signal of the COI gene at the supraspecific level, it is important to note that when DNA barcoding is generated for specific identification, the same specimens should be characterized with another, more conserved, molecular marker that provides information to unravel the evolutionary relationships among subgenera or genera. This requires a consensus to be reached among taxonomists with respect to the marker to be used, which should provide the starting point for a global analysis of all phlebotomine species. 


\section{Funding}

This study was financed by the University of Sucre.

\section{Conflict of interest}

The authors of this study do not declare any conflict of interest.

\section{Acknowledgements}

To Luis Enrique Paternina M.Sc. for his valuable comments. 


\section{References}

Abonnenc, E., Léger, N., 1976. Sur une classification rationnelle des diptères Phlebotomidae. Cah. ORSTOM, ser. Ent. Med. Parasitol. 14, 69-78.

Altschul, S.F., Gish, W., Miller, W., Myers, E.W., Lipman, D.J., 1990. Basic local alignment search tool. J. Mol. Biol. 215, 403-410.

Artemiev, M.M., 1991. A classification of the subfamily Phlebotominae. Parassitologia 33 (Suppl), 69-77.

Azpurua, J., De La Cruz, D., Valderama, A., Windsor, D., 2010. Lutzomyia sand fly diversity and rates of infection by Wolbachia and an exotic Leishmania species on Barro Colorado Island, Panama. PLoS Negl. Trop. Dis. 4, e627.

Barretto, M.P., 1955. Sobre a sistemática da subfamilia Phlebotominae Rondani (Diptera, Psychodidae). Rev. Bras. Entomol. 3, 173-190.

Barretto, M.P., 1962. Novos subgêneros de Lutzomyia França, 1924. (Diptera, Psychodidae, subfamília Phlebotominae). Rev. Inst. Med. Trop. Sao Paulo 4 , 91-100.

Bejarano, E.E., 2001. Nuevas herramientas para la clasificación taxonómica de los insectos vectores de leishmaniosis: utilidad de los genes mitocondriales. Biomédica 21, 182-191.

Bejarano, E.E., 2002. Sobre la evolución de los flebotomíneos americanos (Diptera: Psychodidae): un llamado a los sistemáticos moleculares. Rev. Col. Entomol. 28. 211-212. 
Bejarano, E.E., Castro, M., Pérez-Doria, A., Hernández-Oviedo, E., Vélez, A., Vélez, I.D., 2007. First Report of Lutzomyia Franca in the department of Guainia, Amazonian Colombia, and of Brumptomyia mesai Sherlock (Diptera: Psychodidae) in the Colombian Caribbean Coast. Neotrop. Entomol. 36, 990-993.

Benson, D.A., Karsch-Mizrachi, I., Lipman, D.J., Ostell, J., Sayers, E.W., 2010. GenBank. Nucleic Acids Res. 38, D46-51.

Cohnstaedt, L.W., Beati, L., Caceres, A.G., Ferro, C., Munstermann, L.E., 2011. Phylogenetics of the phlebotomine sand fly group Verrucarum (Diptera: Psychodidae: Lutzomyia). Am. J. Trop. Med. Hyg. 84, 913-922.

Contreras-Gutiérrez, M., Vivero, R., Vélez, I., Porter, C., Uribe, S., 2014. DNA barcoding for the identification of sand fly species (Diptera, Psychodidae, Phlebotominae) in Colombia. PLoS One 9, e85496.

Depaquit, J., 2014. Molecular systematics applied to Phlebotomine sandflies: review and perspectives. Infect. Genet. Evol. 28, 744-56.

Fairchild, G.B., 1955. The relationships and classification of the Phlebotominae (Diptera: Psychodidae). Ann. Entomol. Soc. Am. 48, 182-196.

Florin, D.A., Davies, S.J., Olsen, C., Lawyer, P., Lipnick, R., Schultz, G., Rowton, E., Wilkerson, R., Keep, L., 2011. Morphometric and molecular analyses of the sand fly species Lutzomyia shannoni (Diptera: Psychodidae: Phlebotominae) collected from seven different geographical areas in the southeastern United States. J. Med. Entomol. 48, 154-166.

Folmer, O., Black, M., Hoeh, W., Lutz, R., Vrijenhoek, R., 1994. DNA primers for amplification of mitochondrial cytochrome c oxidase subunit I from diverse metazoan invertebrates. Mol. Mar. Biol. Biotechnol. 3, 294-299.

Forattini, O.P., 1973. Entomologia Medica. Psychodidae. Leishmanioses. Bartonelose. Vol IV. Edgard Blucher, São Paulo, Brazil. 
Galati, E.A.B., 2003a. Morfologia e Taxonomia. Classificação de Phlebotominae, in: Rangel, E.F., Lainson, R. (Eds.), Flebotomíneos do Brasil. Fiocruz, Rio de Janeiro, pp. 23-51.

Galati, E.A.B., 2003b. Morfologia e Taxonomia. Morfologia, Terminologia de Adultos e Identificação dos Táxons da América, in: Rangel, E.F., Lainson, R. (Eds.), Flebotomíneos do Brasil. Fiocruz, Rio de Janeiro, pp. 53-175.

Galati, E.A.B., 2011. Phlebotominae (Diptera, Psychodidae). Classificação, morfologia, terminologia e identificação de Adultos. Vol. I. Apostila de Bioecologia e Identificação de Phlebotominae 2011. Universidade de São Paulo, Brasil.

Hebert, P.D., Cywinska, A., Ball, S., deWaard, J., 2003. Biological identifications through DNA barcodes. Proc. R. Soc. B. 270, 313-321.

Hebert, P.D., Penton, E.H., Burns, J.M., Janzen, D.H., Hallwachs, W., 2004. Ten species in one: DNA barcoding reveals cryptic species in the neotropical skipper butterfly Astraptes fulgerator. Proc. Natl. Acad. Sci. U. S. A. 101, 14812-14817.

Holdridge, L.R., 1967. Life zone ecology. Tropical Science Center, San José.

Hoyos, R., Uribe, S., Vélez, I., 2012. Typification of colombian specimens of Lutzomyia longipalpis (Diptera: Psychodidae) by Barcoding. Rev. Colomb. Entomol. 38, 134-140.

INS, 2005-2014. Subdirección de Vigilancia y Control en Salud Pública. Sistema de Vigilancia en Salud Pública - SIVIGILA. Años 2005-2014. Instituto Nacional de Salud, Bogotá.

Kato, H., Cáceres, A.G., Gomez, E.A., Mimori T., Uezato H., Hashiguchi Y., 2015. Genetic divergence in populations of Lutzomyia ayacuchensis, a vector of Andean-type cutaneous leishmaniasis, in Ecuador and Peru. Acta. Trop. 141, 79-87

Kimura, M., 1980. A simple method for estimating evolutionary rates of base substitutions through comparative studies of nucleotide sequences. J. Mol. Evol. 16, 111-120.

Kocher, A. , Gantier, J.C., Holota, H., Jeziorski, C., Coissac, E., Bañuls, A.L., Girod, R., Gaborit, P., Murienne, J., 2015. Complete mitochondrial genome of Lutzomyia (Nyssomyia) umbratilis (Diptera: Psychodidae), the main vector of Leishmania guyanensis. Mitochondrial DNA. 1-3 
Kumar, N. P., Srinivasan, R., Jambulingam, P., 2012. DNA barcoding for identification of sand flies (Diptera: Psychodidae) in India. Mol. Ecol. Resour. 12, 414-420.

Laurito, M., Oliveira, T.M., Almirón, W.R., Sallum, M.A., 2013. COI barcode versus morphological identification of Culex (Culex) (Diptera: Culicidae) species: a case study using samples from Argentina and Brazil. Mem. Inst. Oswaldo. Cruz. 108, 110-122.

Lewis, D.J., Young, D.G., Fairchild, G.B., Minter, D.M., 1977. Proposals for a stable classification of the phlebotomine sandflies (Diptera:Psychodidae). Syst. Entomol. 2, 319-332.

Librado, P., Rozas, J., 2009. DnaSP v5: a software for comprehensive analysis of DNA polymorphism data. Bioinformatics. 25, 1451-1452.

Lou, M.G., Golding. B., 2007. FINGERPRINT: visual depiction of variation in multiple sequence alignments. Mol. Ecol. Notes. 7, 908-914.

Maroli, M., Feliciangeli, M.D., Bichaud, L., Charrel, R.N., Gradoni, L., 2013. Phlebotomine sandflies and the spreading of leishmaniases and other diseases of public health concern. Med. Vet. Entomol. 27, 123-147.

Martins, A.V., Williams, P., Falcão, A.L., 1978. American sand flies (Diptera, Psychodidae, Phlebotominae). Academia Brasileira de Ciências, Rio de Janeiro, Brazil.

Meier, R., Zhang, G., Ali, F., 2008. The use of mean instead of smallest interspecific distances exaggerates the size of the "barcoding gap" and leads to misidentification. Syst. Biol. 57, 809813.

Nzelu, C.O., Cáceres, A.G., Arrunátegui-Jiménez, M.J., Lañas-Rosas, M.F., Yañez-Trujillano, H.H., Luna-Caipo, D.V., Holguín-Mauricci, C.E., Katakura, K., Hashiguchi, Y., Kato, H. DNA barcoding for identification of sand fly species (Diptera: Psychodidae) from leishmaniasisendemic areas of Peru. Acta. Trop. 145, 45-51.

Pérez-Doria, A., Bejarano, E.E., Hernández, E., 2009. Brumptomyia hamata (Psychodidae), A new addition to the Phlebotomine fauna of the Colombian Caribbean. Acta Biol. Colomb. 14, 135140. 
Pérez-Doria, A.J., Hernández, E., Bejarano, E.E., 2008a. Lutzomyia (Diptera: Psychodidae) from the Reserva Serranía de Coraza y Montes de María, Colombia. Rev. Col. Entomol. 34, 98-101.

Pérez-Doria, A., Bejarano, E.E., Sierra, D., Vélez, I.D., 2008b. Molecular evidence confirms the taxonomic separation of Lutzomyia tihuiliensis from Lutzomyia pia (Diptera: Psychodidae) and the usefulness of pleural pigmentation patterns in species identification. J. Med. Entomol. 45, 653-659.

Posada, D., 2008. jModelTest: phylogenetic model averaging. Mol. Biol. Evol. 25, 1253-1256.

Roe, A.D., Sperling, F.A., 2007. Patterns of evolution of mitochondrial cytochrome c oxidase I and II DNA and implications for DNA barcoding. Mol. Phylogenet. Evol. 44, 325-345.

Saitou, N., Nei, M., 1987. The neighbor-joining method: a new method for reconstructing phylogenetic trees. Mol. Biol. Evol. 4, 406-425.

Scarpassa, V.M., Alencar, R.B., 2013. Molecular taxonomy of the two Leishmania vectors Lutzomyia umbratilis and Lutzomyia anduzei (Diptera: Psychodidae) from the Brazilian Amazon. Parasite Vector. 6, 1-11.

Srivathsan, A., Meier, R., 2012. On the inappropriate use of Kimura-2-parameter (K2P) divergences in the DNA-barcoding literature. Cladistics. 28, 190-194.

Tamura, K., Nei, M., 1993. Estimation of the number of nucleotide substitutions in the control region of mitochondrial DNA in humans and chimpanzees. Mol. Biol. Evol. 10, 512-526.

Tamura, K., Peterson, D., Peterson, N., Stecher, G., Nei, M., Kumar, S., 2011. MEGA5: molecular evolutionary genetics analysis using maximum likelihood, evolutionary distance, and maximum parsimony methods. Mol. Biol. Evol. 28, 2731-2739.

Theodor, O., 1965. On the classification of American Phlebotominae. J. Med. Entomol. 2, 171-197. van Velzen, R., Weitschek, E., Felici, G., Bakker, F.T., 2012. DNA barcoding of recently diverged species: relative performance of matching methods. PLoS One. 7, e30490.

Xia, X., Xie, Z., 2001. DAMBE: software package for data analysis in molecular biology and evolution. J. Hered. 92, 371-373. 
Xia, X., Xie, Z., Salemi, M., Chen, L., Wang, Y., 2003. An index of substitution saturation and its application. Mol. Phylogenet. Evol. 26, 1-7.

Xia, X., Lemey, P., 2009. Assessing substitution saturation with DAMBE. Practice, in: Lemey, P., Salemi, M., Vandamme, A.M., (Eds.), The phylogenetic handbook: a practical approach to DNA and protein phylogeny, second ed. Cambridge University Press, New York, pp. 615-630.

Young, D. G., 1979. A review of the bloodsucking psychodid fies of Colombia (Diptera: Phlebotominae and Sycoracinae). Institute of Food and Agricultural Sciences, University of Florida, Gainesville, Florida.

Young, D.G., Duncan, M.A., 1994. Guide to the identification and geographic distribution of Lutzomyia sand flies in Mexico, the West Indies, Central and South America (Diptera:

Psychodidae). Mem. Am. Entomol. Gainesville, Florida. 


\section{Figure and table captions}

Fig. 1. Distribution of heterogeneity (A) and variability (B) per nucleotide site on the $681 \mathrm{bp}$ sequence of the COI gene of 20 phlebotomine sand fly species of the Colombian Caribbean. 


\section{A}

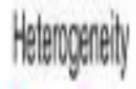

\section{IA IG II IC}

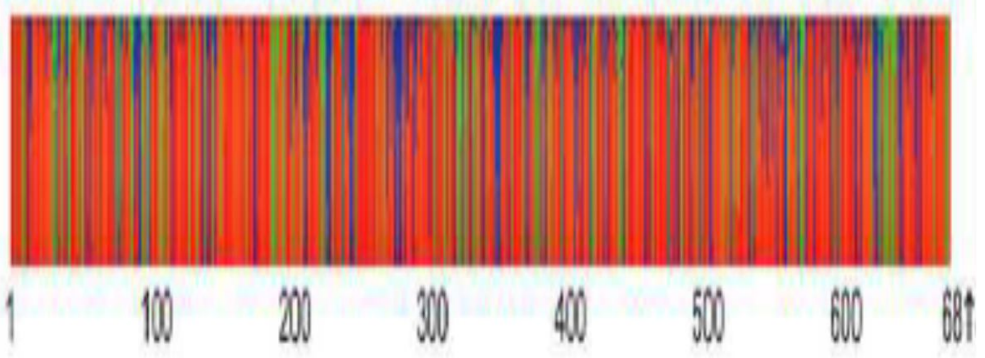

B
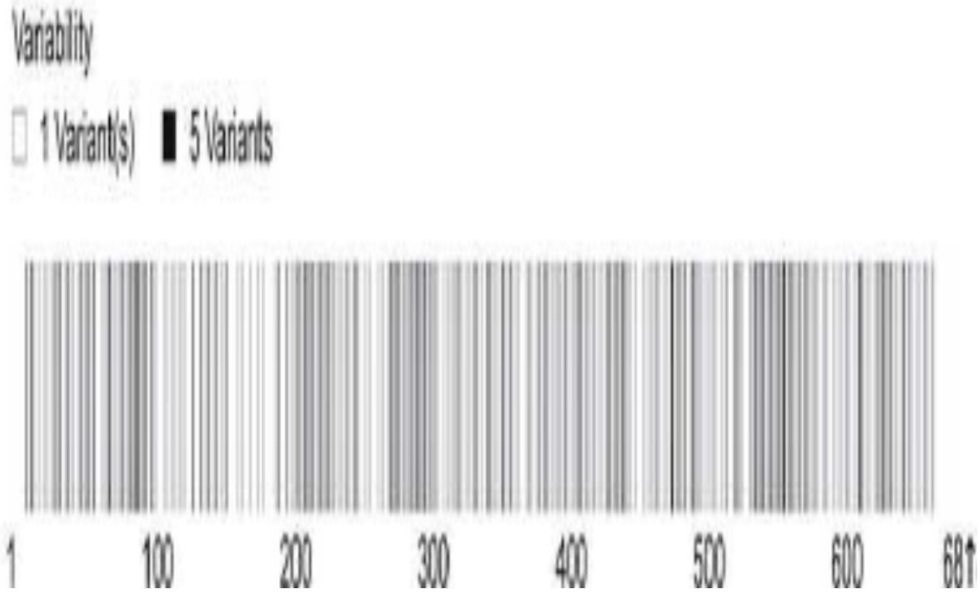

Fig. 2. Neighbor-joining trees based on the model of Tamura \& Nei (1993) (A) and Kimura's twoparameter model (1980) (B). The analysis involved 66 nucleotide sequences of 20 species of phlebotomine sand flies of the Colombian Caribbean. Bootstrap support was estimated by means of 1000 replicas, only bootstrap values $>50 \%$ being shown above the branch. The symbol $\boldsymbol{\Delta}$ corresponds 
to nodes that group individuals of the same species, while $\bullet$ corresponds to nodes with high bootstrap value that group species.
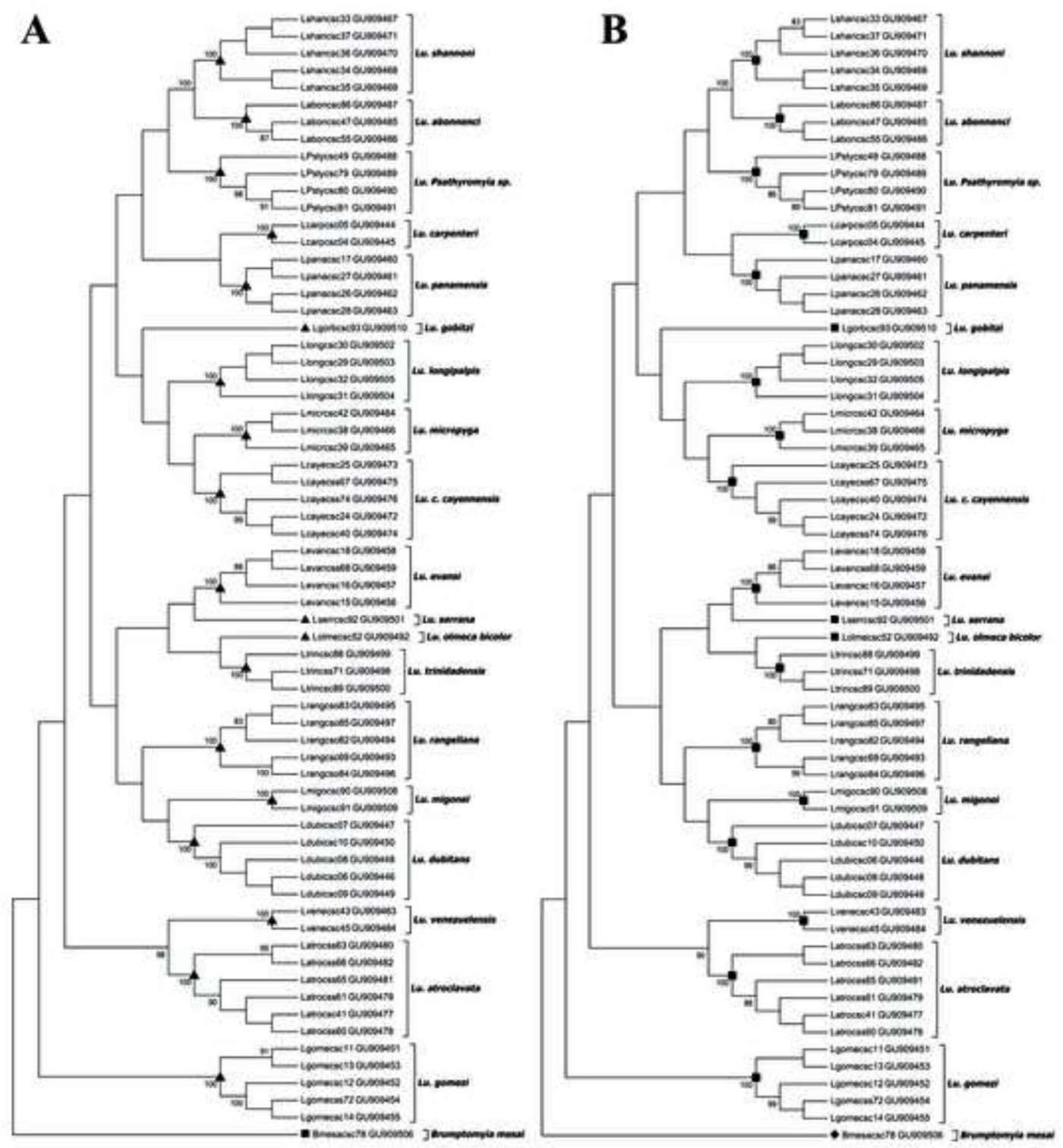

Table 1.

Species of phlebotomine sand flies of the genera Lutzomyia and Brumptomyia characterized by DNA barcoding. For each species are indicated the number of specimens (n) and haplotypes $(\mathrm{H})$, the sex, collection locality, Genebank access number and maximum and minimum values of intraspecific divergence, estimated by means of the Kimura two- parameter model 1980 (K2P) and that of Tamura \& Nei 1993 (TN93). The mean values of the intraspecific distances are indicated in brackets. 
Table 2. Minimum and maximum percentages of interspecific divergence in 20 species of phlebotomine sand flies of the Colombian Caribbean, estimated by means of the model of Tamura \& Nei (1993) (TN93) and Kimura's two parameter model (1980) (K2P). The latter are shown in brackets.

\section{Tables}

\section{Table 1}

\begin{tabular}{|c|c|c|c|c|c|c|c|}
\hline Species & $\mathrm{n}$ & Sex & Locality & $\mathrm{H}$ & TN93 distances & $\mathrm{K} 2 \mathrm{P}$ distances & Accession number \\
\hline$\overline{\text { Lu. abonnenci }}$ & 3 & $\mathrm{~F}$ & Colosó & 3 & $0.1-0.9(0.60)$ & $0.1-0.9(0.57)$ & GU909485-87 \\
\hline \multirow[t]{2}{*}{ Lu. atroclavata } & 2 & $\mathrm{~F}$ & Sincelejo & 5 & $0-0.9(0.49)$ & $0-0.9(0.47)$ & GU909477-82 \\
\hline & 4 & M & & & & & \\
\hline Lu. bicolor & 1 & $\mathrm{~F}$ & Colosó & - & - & - & GU909492 \\
\hline Lu. carpenteri & 2 & M & Colosó & 1 & 0 & 0 & GU909444—45 \\
\hline \multirow{2}{*}{ Lu. c. cayennensis } & 3 & $\mathrm{~F}$ & Sincelejo & 3 & $0-1.6(0.97)$ & $0-1.5(0.93)$ & GU909472-76 \\
\hline & 2 & M & & & & & \\
\hline \multirow[t]{2}{*}{ Lu. dubitans } & 3 & $\mathrm{~F}$ & Colosó & 4 & $0-3.2(1.33)$ & $0-2.9(1.19)$ & GU909446-50 \\
\hline & 2 & M & & & & & \\
\hline \multirow[t]{3}{*}{ Lu. evansi } & 2 & $\mathrm{~F}$ & Colosó & 4 & $0.8-1.8(1.21)$ & $0.7-1.6(1.12)$ & GU909456-59 \\
\hline & 1 & M & Colosó & & & & \\
\hline & 1 & M & Sincelejo & & & & \\
\hline \multirow[t]{3}{*}{ Lu. gomezi } & 1 & $\mathrm{~F}$ & Colosó & 3 & $0-2.5(1.70)$ & $0-2.4(1.51)$ & GU909451-55 \\
\hline & 3 & M & Colosó & & & & \\
\hline & 1 & M & Sincelejo & & & & \\
\hline Lu. gorbitzi & 1 & $\mathrm{~F}$ & Colosó & - & - & - & GU909510 \\
\hline Lu. longipalpis & 4 & M & Colosó & 4 & $0.3-0.8(0.53)$ & $0.3-0.7(0.47)$ & GU909502-05 \\
\hline \multirow[t]{2}{*}{ Lu. micropyga } & 2 & $\mathrm{~F}$ & Colosó & 3 & $0.1-0.3(0.19)$ & $0.1-0-3(0.17)$ & GU909464-66 \\
\hline & 1 & M & & & & & \\
\hline Lu. migonei & 2 & M & Colosó & 1 & 0 & 0 & GU909508-09 \\
\hline \multirow[t]{2}{*}{ Lu. panamensis } & 1 & $\mathrm{~F}$ & Colosó & 4 & $0.6-1.3(0.97)$ & $0.6-1.2(0.90)$ & GU909460 \\
\hline & 3 & M & & & & & \\
\hline \multirow{2}{*}{ Lu. (Psathyromyia) sp. } & 1 & $\mathrm{~F}$ & Colosó & 3 & $0-2.5(1.35)$ & $0-2.2(1.20)$ & GU909488-91 \\
\hline & 3 & M & & & & & \\
\hline \multirow[t]{2}{*}{ Lu. rangeliana } & 1 & $\mathrm{~F}$ & Sincelejo & 5 & $0.1-3.2(1.96)$ & $0.1-2.9(1.80)$ & GU909493—97 \\
\hline & 4 & $\mathrm{~F}$ & Ovejas & & & & \\
\hline Lu. serrana & 1 & $\mathrm{~F}$ & Colosó & - & - & - & GU909501 \\
\hline \multirow[t]{2}{*}{ Lu. shannoni } & 2 & $\mathrm{~F}$ & Sincelejo & 5 & $0.6-1.4(0.95)$ & $0.7-1.3(0.88)$ & GU909467—71 \\
\hline & 3 & M & & & & & \\
\hline \multirow[t]{2}{*}{ Lu. trinidadensis } & 1 & $\mathrm{~F}$ & Sincelejo & 3 & $1.4-1.9(1.56)$ & $1.3-1.8(1.47)$ & GU909498-500 \\
\hline & 1 & M & Sincelejo & & & & \\
\hline
\end{tabular}




\begin{tabular}{lllllccl} 
& 1 & $\mathrm{M}$ & Colosó & & & & \\
Lu. venezuelensis & 2 & $\mathrm{M}$ & Colosó & 2 & $0-0.1$ & $0-0.1$ & GU909483-84 \\
B. mesai & 1 & $\mathrm{M}$ & Colosó & - & - & - & GU909506 \\
\hline
\end{tabular}




\section{Table 2}

\begin{tabular}{|c|c|c|}
\hline Species & Minimun TN93 (K2P) & Maximum TN93 (K2P) \\
\hline Lu. abonnenci & Lu. shannoni, 8.8 (6.8) & Lu. evansi, 42.7 (19.6) \\
\hline Lu. atroclavata & Lu. venezuelensis, 9.5 (7.2) & Lu. abonnenci, 34.1 (17.5) \\
\hline Lu. carpenteri & Lu. panamensis, 17 (11.9) & Lu. gomezi, 40.1 (18.5) \\
\hline Lu.c. cayennensis & Lu. micropyga, 17.7 (11.6) & Lu. trinidadensis, 43.7 (Lu. abonnenci, 18.9) \\
\hline Lu. dubitans & Lu. migonei, 20.4 (13.1) & Lu. (Psathyromyia) sp., 38.8 (Lu. trinidadensis, 18.2) \\
\hline Lu. evansi & Lu. serrana, $20.6(13)$ & Lu. abonnenci, 42.7 (Lu. abonnenci and Lu. shannoni, 19.6) \\
\hline Lu. gomezi & Lu. atroclavata, 21 (13.1) & Lu. trinidadensis, 41.8 (Lu. bicolor, 18.8) \\
\hline Lu. gorbitzi & Lu. micropyga, $21.2(12.8)$ & Lu. gomezi, 41 (Lu. abonnenci, 18.5) \\
\hline Lu. longipalpis & Lu. micropyga, 19.6 (12.8) & Lu. abonnenci, 34.4 (Lu. shannoni, 17.7) \\
\hline Lu. micropyga & Lu. venezuelensis, 15.7 (11.1) & Lu. rangeliana, 34.2 (Lu. abonnenci, 16.6) \\
\hline Lu. migonei & Lu. atroclavata, 17.2 (11.6) & Lu. gomezi, 37.3 (17.7) \\
\hline Lu. bicolor & Lu. venezuelensis, 19.1 (12.6) & Lu. gomezi, 40.9 (18.8) \\
\hline Lu. panamensis & Lu. venezuelensis, 16.9 (11.7) & Lu. trinidadensis, 39.2 (Lu. rangeliana, 18.1$)$ \\
\hline Lu. (Psathyromyia) $) \mathrm{sp}$. & Lu. shannoni, 23.7 (Lu. shannoni and Lu. carpenteri, 14.4) & Lu. trinidadensis, 40.6 (Lu. rangeliana, 19.1$)$ \\
\hline Lu. rangeliana & Lu. migonei, 20.6 (13.1) & Lu. shannoni, 40.3 (19.2) \\
\hline Lu. serrana & Lu. evansi, 20.6 (13) & Lu. gorbitzi, 35.8 (Lu. dubitans, 17.7) \\
\hline Lu. shannoni & Lu. abonnenci, 8.8 (6.8) & Lu. trinidadensis, 41.5 (Lu. evansi, 19.6) \\
\hline Lu. trinidadensis & Lu. bicolor, 22.8 (13.7) & Lu.c. cayennensis, 43.7 (Lu. shannoni, 19.4) \\
\hline Lu. venezuelensis & Lu. atroclavata, 9.5 (7.2) & Lu. (Psathyromyia) sp., 34.9 (17.7) \\
\hline B. mesai & Lu. atroclavata, 19.8 (12.4) & Lu. gorbitzi, 38.4 (17.7) \\
\hline
\end{tabular}


